\title{
Juan García Ponce: entre el amor y el deseo
}

\section{Juan García Ponce: between Love and Desire}

\author{
Armando Pereira \\ pereira@unam.mx \\ Instituto de Investigaciones Filológicas, UNAM
}

RESUMEN: Uno de los principales aspectos que caracterizan la obra de Juan García Ponce es la minuciosa exploración que realiza de la vida íntima de sus personajes y de las relaciones que establecen entre sí. Esas relaciones están marcadas, siempre o casi siempre, por un cúmulo de sensaciones y emociones que unas veces conducen al amor y otras veces al erotismo. Al

Palabras clave:

amor;

deseo;

matrimonio;

escapar;

rizoma. análisis de estos movimientos afectivos, en la escritura de García Ponce, está dedicado este ensayo.

ABSTRACT: One of the principal aspects of Juan García Ponce's narrative is the meticulous exploration of

KEYWORDS:

Love;

Desire;

Marriage;

Escape;

Rhizome. the intimate life of his characters and the relationships between them. These relationships are almost always marked by sensations and emotions which sometimes lead to love and sometimes to erotism. This article is dedicated to the analysis of these affective movements in the writing of Juan García Ponce.

recepción: 1 marzo 2018.

aceptación: 20 agosto 2018.

Si algún lector ocioso de la obra de Juan García Ponce intentara llevar a cabo un minucioso y exhaustivo recuento de los personajes que recorren sus libros, se daría cuenta, al poco tiempo, de que se trata de una labor interminable, pero sobre todo absurda. No sólo porque esos personajes son legión, sino porque en realidad se repiten, de un relato a otro, como una misma imagen en espejos enfrentados. Se trata más bien de una mis- 
ma pareja, a veces un hombre y una mujer, otras veces dos mujeres; en ocasiones, esa pareja se abre para incluir en ella a un tercero, que por lo general será siempre un tercero bienvenido, anhelado incluso; ese invitado que, según Pierre Klossowski, debe ser recibido en casa, por la pareja anfitriona, de acuerdo a las Leyes de la Hospitalidad (cfr. 1975a).

No es la configuración de personajes lo que en realidad le preocupa a García Ponce. No le interesa crear una Madame Bovary, una Ana Karenina, un capitán Ahab. De ahí que muchos de los personajes de sus libros aparezcan apenas delineados, con rasgos imprecisos, evanescentes, como si prefiriera dejar a la imaginación del lector su configuración definitiva. Lo que en realidad le preocupa al escritor yucateco es lo que esos personajes, a través de sus actos, de sus emociones, de sus imprevisibles movimientos en el texto, puedan revelar de sí mismos, de su propia interioridad nunca explícita, desconocida incluso para ellos, esa otra dimensión de uno mismo que sólo la interacción con otros hace que aparezca ante nuestros ojos como la escenificación de un espectáculo en cuyo centro estamos nosotros, con todo lo que desconocíamos de nosotros mismos. Una revelación, entonces, una epifanía.

El movimiento de esos personajes en el texto nunca sigue un camino previsible, no se dirigen de un punto de partida a una resultante final, inscrita ya de antemano en el movimiento inicial. Tampoco se dirigen a un sitio específico, no quieren llegar a ninguna parte. Es como si se solazaran en el movimiento mismo, azaroso, fortuito, interminable. Parece, más bien, como si se movieran en una red de senderos caprichosos que se cruzan entre sí, unas veces convergentes, otras veces divergentes, que más que responder a un destino prefijado desde el principio, parecen estar ahí tan sólo para evidenciar su disolvencia: la ausencia de todo punto de partida, de todo destino previsible. Como si esos movimientos, comparables con el desplazamiento browniano de una mosca sobre la superficie del cristal de una ventana, sólo respondieran a su propia algarabía, a su dispersión en el espacio, a una suerte de juego sin reglas fijas que terminara negando el recto sentido de la vida.

No se trata, entonces, del movimiento del amor, que suele seguir un curso seguro, por lo general ascendente, que busca incesantemente la solidez de un centro al cual aferrarse, hacerlo crecer, engordar, ese refugio, 
ese único refugio donde la vida es posible. Por lo menos, la vida sancionada por el socius, ${ }^{1}$ ese conjunto de reglas que normaliza los comportamientos humanos, que los domestica, que los hace traducibles a la luz de la conciencia, que elimina de ellos toda su violencia, su intemperancia, toda su fuerza subversiva.

En Unión, una novela breve que Juan publica en 1974, Nicole y José, sus personajes principales, hablan del amor, de lo que ellos entienden por amor, que no coincide plenamente con la versión que la sociedad ha instituido sobre este concepto:

-El amor no es para la vida.

—Dime qué es el amor — contesta ella.

—-Lo que nosotros somos desde fuera, tal vez. Algo que vaga sin dueño (29).

Y es que el amor, según la versión en la que la sociedad se complace y en la única en la que puede reconocerse, es aquel sentimiento que busca sin descanso un "dueño", ese sujeto perfectamente reconocible, con nombre y apellido, único, irrepetible, por el que nos dejamos absorber y al que también absorbemos por completo, sin dejar resquicio entre los dos, hasta formar una sola figura indisoluble, impenetrable, incompartible por nadie que no sea nosotros mismos, monolítica. Pero si el amor, en la versión que propone Juan García Ponce, es "algo que vaga sin dueño", estamos hablando entonces de otra cosa. Estamos hablando de un movimiento distinto, de un movimiento que no tiene nada que ver con la concepción socialmente aceptada de un sentimiento que escapa a toda definición única, inapelable, que quizá se abre a otras configuraciones, a otras figuras menos rígidas, más inclusivas, más discrecionales.

Creo que ahí radica la diferencia básica entre dos sentimientos que recorren la obra completa de Juan García Ponce, y que si por momentos parecen confundirse hasta alcanzar una sola figura unitaria, un instante después los vemos separarse, como si uno huyera insistentemente del otro, como si no quisiera quedar atrapado en esa bifronte figura unitaria, en ese

\footnotetext{
1 Por "socius" se entiende el conjunto de condiciones e instituciones sociales, cuyas normas y reglas establecidas y su sistema de prohibiciones y permisiones determinan la actividad del sujeto en sociedad y hacen posible la continuidad de la vida social.
} 
Jano de doble rostro, como si sólo quisiera construir su propio territorio sin injerencias extrañas, como si asumiera plenamente su diferencia, su especificidad inalienable. $Y$ es que el deseo, en la obra de Juan, no puede confundirse nunca con el amor. No sólo se trata de sentimientos distintos, sino en muchos casos incompatibles: como dos enemigos discretos que se conocen, que se toleran, que se acarician incluso, pero que en ningún momento están dispuestos a abandonar su propio territorio para entregarlo al imperio absoluto del otro.

En algún momento de la novela, Nicole le pregunta a su madre:

—Tú no quieres a José ¿verdad mamá? —dijo.

- Te quiero a ti y espero que tú lo quieras. En la vida se debe tener un centro (70-71).

Esa sencilla afirmación de la madre le permite a Nicole descubrir, en su interior, precisamente la certeza opuesta: su definitivo rechazo de todo centro posible. Ese centro que debía proporcionarle lo que toda gente de bien anhela: estabilidad, consistencia, seguridad, firmeza, equilibrio. Ella, en cambio, se percibe a sí misma de una manera distinta: no anclada en un lugar determinado, en un sujeto determinado, en un cuerpo determinado, sino como una figura móvil, que transita de un punto a otro, que no le interesa el lugar al que va a llegar, que sólo le interesa su propio movimiento. Si José está ahí es sólo para ser abandonado incesantemente, para volver a él incesantemente. No porque constituya un centro necesario, sino porque facilita la posibilidad de un tránsito interminable. La idea de un centro no es más que una ilusión tranquilizadora, ataráxica. Lo que ella busca, más bien, es el riesgo, la fugacidad, el azar, la contingencia. No quiere estar segura de nada; quiere explorar todo territorio posible, entregarse a ese avispero en torno a ella. Sabe que el centro, si existe, está en todas partes y en ninguna, que el deseo que ella experimenta con fuerza carece de un centro que lo fije, que el deseo es precisamente lo contrario: movilidad pura, incesante.

Deleuze y Guattari han enfatizado el carácter rizomático del deseo. Un rizoma es una raíz sui generis que crece bajo la tierra, que no sigue en su crecimiento una dirección precisa, que se mueve en un sentido o en otro, 
sin orden alguno, impredeciblemente. Su movimiento inconstante rechaza la verticalidad, no quiere acceder a la superficie. Se trata, más bien, de ocupar un espacio, el mayor espacio posible, ese espacio subterráneo que habita y en el que se desenvuelve en su decidida horizontalidad, creando constantemente nódulos y abandonándolos en seguida para crear nuevos nódulos y volver a abandonarlos. "En un rizoma no hay puntos o posiciones, como ocurre en una estructura, un árbol, una raíz. En un rizoma sólo hay líneas" (14). Es ese precisamente el movimiento que caracteriza al deseo.

Y ese es también el movimiento de Nicole en la novela. No es uno sino varios los puntos que atraen ese movimiento: está José, desde luego; pero también el hermano de José, con quien Nicole se ha besado, y además está Jean, el amigo francés de José. Y ella gira en torno a ellos como giraría un planeta que ha escapado de su órbita y se divierte en torno a distintos soles.

Jean ha llevado a Nicole a su departamento y hace el amor, pero cada uno se abandona al placer desde perspectivas muy distintas: ella juega; él busca definitivamente otra cosa.

—iMe quieres? —preguntó Jean luego [de hacer el amor].

$[\ldots]$

-No, no te quiero — contestó ella.

Y quizá era imposible explicarlo, pero era verdad; sin embargo, Jean la miró incrédulo.

— ¿Entonces? - dijo.

—No te quiero, pero estoy contigo y me gusta — dijo Nicole (1974: 93).

Lo que Jean busca es algo que está más allá del placer, algo que debe sobrevenir necesariamente después del placer para sellar esa relación y colocarla en un nivel "superior", trascender la "simple" sensación y acceder al sentimiento. La apelación al amor ("¿Me quieres?") en la que él insiste y a la que ella se niega es justamente la apelación al sujeto. Edipo, el sujeto por excelencia, reconoce el lugar de cada personaje en la historia familiar. Ahí están Papá (el nombre de la ley) y Mamá (el objeto del deseo) e inmediatamente teje una historia entre los tres. Desea lo que el padre desea, pero se contiene. Sabe que el objeto del deseo está interdicto por la ley, y obedece; somete su propio deseo al dictum paterno, hasta convertir 
su deseo en algo muy distinto de lo que era originalmente: ya no desea a la madre, ahora la ama, ese sentimiento tranquilizador, inocuo, que hace posible la vida en familia. Acceder a la situación de sujeto, es aceptar la sujeción del deseo a la norma paterna, a la norma social, a esa Institución que normaliza los comportamientos humanos eliminando de ellos toda la fuerza subversiva y antisocial que los caracterizaba en un principio. Es lo que Nietzsche habría Ilamado en el § 356 de La genealogía de la moral, "la moral de esclavo" (cfr. 1983).

La constante que recorre a la mayoría de los personajes femeninos de los cuentos y novelas de García Ponce es la certeza que hay en ellas de no estar nunca seguras de que lo que sienten pueda caber con exactitud en el concepto "amor", como si no quisieran que sus sentimientos quedaran atrapados en esa palabra, simplificados por esa palabra, reduciendo así su diversidad y complejidad bajo el enorme peso de ese Significante socialmente construido para encasillar y encauzar en el discurso de la Institución social un sentimiento en sí mismo inclasificable.

Desde un principio, José conoce el carácter imprevisible del movimiento del deseo en Nicole, es lo que lo atrajo de ella, y lo quiere precisamente así: imprevisible, insumiso, insujetable, rebelde a todo intento de determinación por el socius que lo rodea, por las instituciones (lingüísticas, sociales, culturales) que al calificarlo lo detienen en un territorio (de significación), en un punto fijo que paraliza ese movimiento, que lo anula como tal, que lo convierte precisamente en su contrario: ya no un punto de fuga que quiere escapar de toda sujeción, sino en un punto fijo: inerme, petrificado, impotente, inútil.

El sujeto amoroso parte siempre de un "yo" en el que se reconoce y que lo distingue de todos los demás, y se dirige siempre a un "otro" concreto, único, intransferible, distinguible también de todos los demás. En el amor soy "yo" el que ama a "alguien" que sólo puede ser amado por mí. El lazo entre los dos deja afuera a cualquier otro que intente inmiscuirse en nuestra relación. En el discurso amoroso, la afirmación "te amo" es equivalente a afirmaciones contiguas, consecuentes, metonímicas, que confirman y consolidan la primera sentencia: "eres mía", "soy tuyo". Ese lazo de posesión no sólo excluye la injerencia de un tercero entre nosotros, sino que, al mismo tiempo, nos exilia de la circulación del deseo. Convierte nuestro 
deseo en un deseo esquizofrénico, autofágico, que se devora y nos devora en su propio enclaustramiento. Desde ahora, tú y yo, somos un centro, precisamente ese que el deseo desprecia, del que huye constantemente a través de la deserción de todo punto fijo, a través de la disolución de ese ilusorio sujeto en el que no quiere verse atrapado.

Lacan (1981) llega incluso a afirmar que el amor es una sublimación de una relación sexual que no existe o, para decirlo de una manera un poco más clara, de una relación sexual insatisfactoria: como quiero que permanezcas a mi lado, aunque en nuestra sexualidad no nos hayamos encontrado plenamente, digo te amo. Coloco en una dimensión "superior", "mucho más plena", lo que no existe entre nosotros. Y de ahí al matrimonio — esa Institución social que sanciona y santifica al amor- no hay más que un paso.

Esa historia García Ponce nos la cuenta en otra de sus novelas breves: La casa en la playa. El relato comienza precisamente así: Elena ha sido invitada por Marta, una amiga de la adolescencia, a pasar unas largas vacaciones en su casa de la playa. Allí conoce a Héctor. Desde el primer día, se estrecha la relación entre los dos. Desde el primer día, Héctor insiste en conducir esa relación por los cauces del sentimiento, cuyo objetivo final es siempre (o casi siempre) el amor.

—A veces creo que eres demasiado joven. Para ti todo puede ser un juego, algo nuevo simplemente, y para mí no lo es.

- Tampoco para mí —insistía yo - Ya te dije que te quiero, que creo que te quiero.

- ¿Lo ves? Eso es lo malo. Tienes que agregar el "creo" porque no estás segura. — ¿Cómo se puede estar segura de nada? Lo hago sin darme cuenta. Pero además, creer que te quiero es quererte ya. No puedo ver las cosas de otra manera (1966: 56).

El amor no duda, el amor no es un juego. Es algo serio, que no admite ambigüedades: o se ama o no se ama. El amor exige certezas, que es lo que Héctor le exige a Elena, aunque ella "no puede estar segura de nada", aunque ella "no puede ver las cosas de otra manera". Quizá no es sólo que no puede, sino que no quiere. Tal vez lo que ella quiere es jugar, como juega el deseo con los cuerpos que recorre. 
Al fin, yo misma le propuse que, si no podía llevarme a su casa por su madre, fuéramos a un hotel. Él se negó. Hablábamos ya de que teníamos que casarnos y durante esos primeros meses yo creía que estaba dispuesta a hacerlo, pero era incapaz de pensar en eso como algo inmediato y en cambio sentía cada vez más que deberíamos acostarnos juntos (57).

Irán al hotel, harán el amor, no una sino varias veces. Pero mientras él insiste una y otra vez en el amor que los une y en el matrimonio que debe sellar esa unión, ella comienza a aburrirse:

Su seriedad, la empecinada gravedad con que tomaba todas las cosas, su equilibrio y hasta el sentido de justicia que le hacía sentirse un tanto culpable ante mí, me aburrían mortalmente [...]. Entonces sentía que la sensación de firmeza y autoridad que su persona me daba al principio había desaparecido por completo y ahora era como todos mis novios anteriores, sólo que más aburrido (60; cursivas mías).

Esas "cualidades" que la sociedad enaltece y en las que necesariamente se apoya para posibilitar su continuidad (y que en la cita anterior he destacado en cursivas), son los pilares fundamentales sobre los que se erigen el amor y el matrimonio, esas dos instituciones que le dan verosimilitud y credibilidad a la vida social, que constituyen su sentido y su posibilidad de reproducción. Son cualidades duras, fijas, perdurables a pesar del viento y la lluvia, imperturbables, sobre las que puede edificarse un destino; nada que ver con el carácter inapresable del agua o del viento, nada que ver con el carácter líquido, fluctuante, del deseo (cfr. Bauman 2009). ${ }^{2}$

El deseo no quiere ser serio, prefiere jugar; desertar de las verdades establecidas y saltar de un lugar a otro, aceptando la contingencia y el principio de incertidumbre: está más cerca de Heisenberg que de santo Tomás. Por eso opta por universos ingrávidos, en donde los cuerpos flotan

2 En Tiempos líquidos (2009), Bauman se refiere, no sin cierta preocupación, al cambio de paradigma que está sufriendo nuestra época, al paso de un estado sólido a un estado líquido en los comportamientos humanos y en el que se trastocan todos los valores éticos y sociales. Aunque me parece que el texto podría leerse con beneplácito, sin preocupación alguna, con la alegría de abandonar la fijeza del mármol para acceder a la levedad y a la inconsistencia del agua, que carece de una forma única, que "toma la forma del vaso que la aclara", diría José Gorostiza, esa forma que "en el agua, en el vino, en el aceite, articula el guion de su deseo" (Gorostiza, "Muerte sin fin", en 1964). 
y se penetran, disfrutando de su ausencia de peso, de su levedad. Carece de sentido de justicia; es más, el deseo es injusto por naturaleza, egoísta, autosuficiente, ególatra; por lo general, le hace daño a los demás, a los que no desea; sólo busca su propia satisfacción, sin sentirse culpable por la insatisfacción ajena. La firmeza lo aburre, lo abruma, le produce grima; prefiere los cuerpos blandos, un poco amorfos, inclasificables. Y huye, como de la peste, de la enorme estupidez que se esconde detrás del más mínimo gesto de autoridad. Sabe que la autoridad es tonta, oligofrénica, y, en cuanto la tiene enfrente, se escurre.

Por eso Elena rechaza el amor y el matrimonio que Héctor le ofrece, porque quiere permanecer ingrávida, espuria, inconsistente; porque no quiere desembocar en esa figura hierática y tiesa que necesariamente la espera al final de ese camino que el amor y el matrimonio iniciaron: la maternidad, la familia, el sujeto normalizado, domeñado por las normas, ese territorio en el que la sociedad se solaza y en el que el deseo se extingue, o sólo figura como el gran exiliado.

\section{Se abre paréntesis}

Aunque en términos generales este es el movimiento que siguen los sentimientos, las emociones o los deseos de los personajes en la obra de Juan García Ponce, también es verdad que, en algunos casos, el destino final de esa subjetividad convulsa que ellos configuran no siempre es el mismo, no siempre es el deseo el que triunfa sobre el Imperio de la norma social. En algunos casos, como ocurre en Figura de paja, otra de las grandes novelas cortas de Juan, el deseo resulta vencido por la norma, o por los nefastos efectos del ejercicio de la norma sobre los cuerpos rebeldes.

Desde el principio de la novela, el narrador le deja claro a Alma, una de las distintas mujeres entre las que su deseo se mueve, que no quiere casarse y mucho menos llenarse de hijos, que no quiere formar una familia:

No me había casado porque no quería cambiar de vida y, sobre todo, porque al hacerlo no le hubiera agregado nada nuevo ni verdadero en nuestra relación, ni tampoco hubiera contribuido a hacerla más estrecha. Ninguno de los dos 
quería tener hijos, nos conocíamos muy bien y nada podía cambiar entre nosotros (1979: 91-92).

Incluso, cuando Alma quedó embarazada, ninguno de los dos lo dudó: el aborto desplazó la posibilidad de un matrimonio y de una familia. El narrador de la novela ha dejado que su deseo se mueva libremente tejiendo una complicada red de relaciones íntimas con las tres mujeres que constituyen las aristas de esa figura poligonal en cuyo interior se estructura el juego: Alma, la mujer del narrador; Leonor, su amiga íntima, y Teresa, esa advenediza que aparece de pronto para cerrar el espacio del juego y atraer hacia ella los deseos ambulatorios e informes que lo recorren.

La sola presencia de Teresa ha cambiado repentinamente las reglas originales del juego: lo que comenzó como una simple atracción erótica en torno a la irresistible voluptuosidad del cuerpo de Teresa, de pronto rebasa esos límites para ingresar en un territorio en el que se pierden toda la seguridad y todas las certezas iniciales: ya no es sólo el cuerpo de Teresa lo que el narrador busca insistentemente (como ha buscado también los cuerpos de Alma y de Leonor), sino algo que está más allá del cuerpo y que sin embargo lo conforma, algo intangible, inverificable, que sólo se hace presente a través del amor: su "interioridad", esa zona que desconoce y que nunca antes le había importado demasiado. Ahora quiere poseerla completa, ya no sólo su cuerpo, sino sobre todo su alma, esa "interioridad", esa "subjetividad" que debe constituirla como una "totalidad" y a la que él no sabe cómo acceder, tal vez porque no puede aceptar que esa subjetividad no existe en ninguna parte o, al menos, no existe fuera del cuerpo que anhela. O bien, para decirlo de otra manera, porque se trata de una "sustancia" evanescente y fantasmal que únicamente existe en su propia imaginación alienada en la enigmática figura de Teresa. Ahora ya no la desea; ahora ha empezado a amarla, se ha empeñado en amarla.

Teresa, por su parte, no hace demasiado caso del giro que ha tomado su relación con él. Ella sigue jugando su juego, el juego que desea, que ha deseado siempre. Ante la mirada alelada de su "amado", se entrega a los brazos de Leonor. Bailan las dos, se besan, se acarician una a la otra, mientras él consternado las contempla. Teresa ni siquiera se pregunta por 
el dolor que su repentina elección puede producir en ese pobre hombre que la ama. Sabe que el dolor es una condición necesaria del amor. Si él ha querido enamorarse, allá él. Que sufra en silencio sus emociones, que se hunda en el laberinto afectivo que el amor ha despertado en él. El camino de ella es otro: no rebasa el universo tangible de las sensaciones, no desea internarse en el pantanoso territorio de la sublimación, no quiere engañar a sus sentidos con imágenes sustitutivas e ilusorias, no está dispuesta a abandonar la superficie de los cuerpos para hundirse en la supuesta plenitud de los afectos.

En definitiva, se irá a vivir con Leonor, que hasta ahora, al menos, no le ha exigido otra cosa que no sea el calor de su piel. Aunque tampoco está dispuesta a renunciar a nada. Al poco tiempo, junto a ella, se da cuenta que extraña el cuerpo de su "amado", que quisiera tenerlo a él también allí, entre las dos, jugando ese juego atroz del deseo que es el suyo. Y se lo propone a Leonor, sin darse cuenta que Leonor ha terminado también enamorándose de ella y que no quiere la presencia de nadie más entre las dos. Ante la "insensibilidad" de Teresa, Leonor terminará suicidándose. Y con su suicidio, y los sentimientos de culpa que repentinamente brotan en los sobrevivientes del juego (el narrador y Teresa), esos oscuros sentimientos que hacen imposible la vida, concluye un discurso que quiso ser el emergente y despreocupado discurso del deseo, sin saber que terminaría derrotado por el omnívoro socius que lo rodea.

O como ocurre incluso en otro texto en el que Juan García Ponce parece que se desdijera de todo lo que había afirmado hasta entonces: su franca apuesta por el deseo que recorre los cuerpos frente al amor y todos sus sucedáneos. En "Anticipación", el relato que abre el libro Figuraciones, A-1, uno de sus personajes principales, establece una abierta querella contra el deseo y en favor del amor. En algún momento del texto, dice: "existe la realidad de la presencia y el deseo. ¡Qué estupidez! Todo eso es mentira porque es cierto sólo en tanto es la condición de los imbéciles" (1982: 26). Y es que en el cuento se narra una historia muy íntima, muy personal, de carácter autobiográfico, a la que Juan se ha referido una y otra vez, con mayor o menor precisión, en distintos textos que escribió a lo largo de su vida. Más que una historia, se trata de la recreación de una imagen, la imagen de una adolescente de la que se enamoró, como sólo 
puede enamorarse un sujeto a los 19 años, durante un viaje al pueblo donde había nacido su padre en el norte de España. Se trata entonces del primer amor, ese amor que no está marcado sustancialmente por el deseo, sino que nace como una vivencia interior y que quiere permanecer así, en su propia esfera de idealización, ajena al mundo y a la grosera presencia del cuerpo y del deseo, ese gran amor adolescente al que no volveremos más en ningún otro momento de la vida.

Es lo que precisamente se pierde con el ingreso a la edad adulta. Es lo que precisamente se gana con el ingreso a la edad de la razón, habría dicho Sartre (cfr. 1967b). Eso lo saben muy bien los personajes adultos de las historias de García Ponce, que parecen haber decidido romper con todo gesto romántico, la nostalgia del primer amor, por ejemplo, para entregarse sin culpa alguna a la plenitud del deseo.

\section{Se cierra el paréntesis}

Me parece que ese extraño movimiento del deseo, que recorre a muchos de los personajes de Juan García Ponce y del que hemos tratado de dar cuenta aquí a través del análisis de algunas de sus novelas cortas, alcanza su expresión más lograda y compleja en De ánima, ya no otra novela corta, sino sencillamente una de sus cimas narrativas en la que convergen y culminan algunas de sus preocupaciones anteriores y a partir de la cual brotan nuevos ríos de significación cada vez más caudalosos y vertiginosos.

La forma que adopta la novela es esa forma confesional del diario íntimo o de la novela epistolar que, desde el Werther de Goethe, al menos, ha sido una constante en la literatura de Occidente. Aunque en este caso no se trata de un solo diario, de una sola voz, de una sola intimidad expuesta a la mirada voyeur del lector, sino, como en la novela de Junchiro Tanizaki, The key (1961) (que junto con La revocación del Edicto de Nantes [1975] de Klossowski, constituyen la dos influencias principales en De ánima), de dos diarios (el de una mujer y el de un hombre, Paloma y Gilberto) que dialogan entre sí, que se explican o se corrigen mutuamente, que se complementan hasta lograr, entre los dos, esa imagen unitaria y 
final, aunque por momentos también contradictoria, que se configura a lo largo de la novela.

En la primera entrega de su diario, Paloma revela varias cosas. Ante todo, su edad: treinta años. Si no necesariamente una edad crítica, sí, al menos, una edad en que la mujer (también el hombre) toma la vida en sus manos. Si hasta los treinta años dejamos, en total displicencia, que la vida nos viva, que nos arrastre de un lado a otro, como las olas del mar a un cuerpo muerto, a partir de los treinta algo, tal vez la conciencia de que la juventud se acaba, de que no somos eternos, nos lleva a hacernos cargo de los años que nos quedan, a fijarnos un destino. Y el primer paso de Paloma, en este sentido, ha sido romper uno de los grandes códigos con que la sociedad sanciona la relación de pareja: el matrimonio. Para Paloma, el matrimonio implica un movimiento defensivo contra el deseo, una forma de dejar de estar (o sentirse) disponible hacia los otros, una manera de exiliarse de la circulación del deseo. Su divorcio de Armando, entonces, vuelve a situarla de pronto a expensas del deseo de los demás, a expensas de su propio deseo recobrado.

La relación que, al poco tiempo de su divorcio, entabla con Gilberto es ante todo una relación de conocimiento, en la que ella descubre su cuerpo y las instancias imaginarias que lo constituyen a través de la mirada de Gilberto, que hace posible todo eso. "Si los hombres pueden hacer algo en relación con nosotras - escribe Paloma - es contribuir a revelarnos" (1984: 30). De esta manera, se establece un lazo indisoluble entre la mirada y el cuerpo, un lazo tejido por el deseo. Aunque en la novela de Juan ese lazo apunta también en otro sentido: la mirada no sólo fija cada gesto, cada movimiento, haciéndolos conscientes de sí mismos, sino que también los perfecciona; establece así con el cuerpo contemplado la relación que puede establecerse con la materia que dará lugar a una obra de arte (habría que recordar que el arte nace también del deseo): una relación de perfeccionamiento constante. Y como toda obra de arte, ese cuerpo aleccionado por la mirada — su fruición, su gozo- no puede guardarse avariciosamente para la contemplación solipsista; debe entregarse también a la contemplación y al placer de los otros. Así, ya desde un principio, la novela nos coloca ante una visión del cuerpo y del erotismo que los sitúa fuera de las concepciones convencionales que 
se tienen de ellos y que sitúan a la pareja como el centro indiscutible de ese movimiento. Para Juan García Ponce, el cuerpo y el erotismo constituyen esas zonas de placer y de gozo que deben remitirnos, en última instancia, a una experiencia estética en la que el otro, el tercero, está de antemano incluido.

Si en un primer momento la relación que Paloma entabla con Gilberto es una relación de conocimiento, en la que ella poco a poco descubre su cuerpo y la especificidad del deseo que lo recorre, guiada siempre por la mirada de él, enseguida se dan cuenta los dos que esa relación se despliega en un territorio que no pertenece al amor, sino exclusivamente al erotismo. "Llegamos a mi casa y me usó y la usé. Nos usamos" (35), dice Gilberto. Y, en realidad, no es el amor (ni el cariño, ni la ternura), sino la noción de uso, la que recorre de principio a fin el vínculo edificado entre ellos.

Este punto, en el momento de la publicación de la novela, generó una especie de revuelo, aunque no siempre indignado, en la crítica feminista. Se la consideró como un discurso abiertamente machista que hacía de la mujer un simple objeto de uso al servicio del placer del macho, que objetualizaba a la mujer al grado de convertirla únicamente en un cuerpo manipulable, eliminando de ella su calidad de sujeto. Ya no era una persona, sino un utensilio que el macho utilizaba para obtener una plusvalía placentera. Una lectura, en algunos casos, bastante tergiversada y tergiversadora. ${ }^{3}$ En primer término, habría que evidenciar que no es sólo él el que la usa a ella; también ella lo usa a él para obtener su propia dosis de placer. Se usan mutuamente, siempre con el beneplácito del otro. Y es aquí donde radica el aspecto esencial de la cuestión. Si yo deseo que me uses, si yo te pido que hagas de mí el objeto de tu gozo, no desaparezco como sujeto, más bien al contrario: asumo plenamente mi condición de sujeto al elegir libremente que me conviertas en el objeto de tu placer.

3 Cfr. Lilia Deriben y Dominique Legrand. "JGP: soy la tautología viviente", en "Sábado", núm. 235 (8 de mayo de 1982): 10-11; Nedda G. de Anahalt, "De ánima, todo sigue igual pero diferente", en "Sábado", núm. 350 (14 de julio de 1984):12; "Sábado", núm. 351 (21 de julio de 1984): 10; Silvia Sigüenza. "La novela erótica de JGP (De ánima)", en Punto, núm. 189 (16 de junio de 1986): 22; Graciela Gliemmo. "Crónica de la intervención: el desnudo de una escritura", en Hispamérica, vol. 20, núm. 58 (abril de 1991): 17-27. 
Puede tratarse de una elección extraña, perversa incluso. Pero la elección, cualquiera que esta sea, es la condición esencial que nos convierte en sujetos. La idea no es mía, sino de Sartre: "Sólo en el momento de elegir somos libres" (cfr. 1967a y 1967c). ${ }^{4}$

En el caso de los personajes de Juan García Ponce, esa elección no sigue los caminos rectos y honorables que la sociedad ofrece, no se somete a las normas de las buenas conciencias y de la virtuosa convivencia; sigue, más bien, caminos tortuosos, incoherentes, fortuitos, inconsecuentes, caminos dictados más por el deseo que por el decoro. De ahí que su elección no sea el amor, sino el erotismo. En una relación estrictamente erótica no se ama, sino que se usa al otro para alcanzar el placer anhelado. Allí, el amor o la ternura podrían convertirse incluso en un obstáculo para el placer. Roland Barthes señala: "El placer sexual no es metonímico: una vez tomado, se le corta [...] La ternura, por el contrario, no es más que una metonimia infinita, insaciable; el gesto, el episodio de ternura [...] no puede interrumpirse sino con aflicción" (243). Y son precisamente esas emociones sustitutivas - amor, ternura, cariño, aflicción- las que el sujeto erótico trata a toda costa de evitar, en la medida en que podrían debilitar (o incluso suprimir) la intensidad del placer buscado.

Para el erotismo, la noción de corte es esencial. El objetivo único de sus prácticas es la obtención del placer. Una vez alcanzado ese objetivo, la relación erótica se corta, termina, sencillamente porque ha sido satisfecha plenamente. No busca prolongarse en emoción alguna, las emociones están ausentes en esa relación. Pertenecen a otro registro — el amor-que no tiene nada que ver con el erotismo. El sujeto amoroso no corta nada, porque su juego se desenvuelve en otro escenario. Su objetivo esencial no es el placer, tampoco el gozo. El placer y el gozo, para él, son sólo instrumentos que le permiten alcanzar una dimensión superior, según él, que trasciende al cuerpo, que sublima toda instancia sensitiva para construir el espacio de las emociones, de los sentimientos, el territorio del alma del que el placer y el gozo han sido exiliados en favor de la "historia de amor", esa construcción metonímica que se prolonga interminablemente de un sentimiento a otro: el amor, la ternura, el cariño, la posesión, la pérdida,

\footnotetext{
4 En realidad, esta idea es central en toda su obra y la recorre de principio a fin.
} 
la tristeza, la aflicción, la nostalgia: el drama, al fin y al cabo (cfr. Kristeva 1988). Esa "historia de amor" en la que el cuerpo es el gran ausente. Es a esa "historia de amor" a la que Gilberto y Paloma se oponen, la que rechazan decididamente. Gilberto no se cansa de decirlo: "no es una posesión y tampoco es el amor, son nuestros cuerpos y lo que nuestros cuerpos hacen de nosotros [...] Es hermoso no amarla sino tan sólo desearla" (García Ponce 1984: 48-49).

Si no es amor y tampoco posesión, a la que de una manera natural lleva el amor, entonces esa relación puede desbordarse, puede rebasar a los dos cuerpos entre los que se establece y alcanzar a otros cuerpos, cuya presencia allí, más que obturar, estimula el deseo. Es lo que le ocurre a Paloma en esa reunión a la que ha acompañado a Gilberto. Al calor de las copas, comienza a quitarse la ropa, a sentarse en las piernas de uno de los invitados, a bailar desnuda con los amigos de Gilberto, a dejarse acariciar por esas manos que, por ser de todos, no pertenecen a nadie en particular, como el deseo mismo que, por su carácter preedípico, carece de nombre y apellido, no es de nadie y es de todos a la vez, rechaza la especificidad del sujeto, disfruta del anonimato de los cuerpos.

Pero esa escenografía que un solo gesto suyo ha desplegado de pronto, aunque originalmente no estaba destinada a nadie, enseguida encuentra a un espectador privilegiado, que sabe apropiársela y disfrutarla como ninguno, incluso dirigirla, moldearla, es decir: perfeccionarla. Gilberto durante toda la noche no ha despegado los ojos de ella, goza al verla entregarse a otros hombres, al verla hilvanar las infinitas posibilidades de seducción inscritas en su cuerpo, al verla explorar las distintas Palomas que hasta ahora la habitaban en silencio. También ella, por su parte, se descubre a sí misma en la mirada aquiescente y divertida de Gilberto, y eso la excita aún más. Luego, cuando vuelva a estar sola en la cama con él, encontrará el sentido preciso de ese juego: "Cuando nos acostamos su deseo [el de Gilberto] era también el deseo de todos los demás. Nadie es nadie mientras hace el amor" (64). Y es que allí, en la relación erótica, el amor es el gran ausente. El amor apela al sujeto edípico, constituido en el triángulo familiar y donde ha aprendido a amar y a odiar, donde se ha sometido al largo proceso de aprendizaje de los sentimientos que le permiten reconocerse como sujeto completo: ahí está su cuerpo, sí, 
pero también y sobre todo esas instancias afectivas que constituyen su subjetividad y que, al mismo tiempo, busca, en el otro, su semejante. Nada más lejano de Paloma, que insistentemente se niega a hablar de amor, que prefiere hablar de deseo, pues de alguna manera sabe que el deseo no se afirma tanto en los afectos sino en las sensaciones. Y en el terreno movedizo de las sensaciones, el sujeto del deseo es siempre plural, indistinguible. "El gusto que le daba a Gilberto que yo les guste a otros también hace más difícil para mí mantenerme dentro de ciertos límites" (59).

Imperceptiblemente, comienza a prefigurarse en el texto un incesante juego de reflejos en el que, como en el arte, la imagen original queda atrapada. Si el cuerpo desnudo de Paloma, al entregarse a otros cuerpos, absorbe la mirada de Gilberto, esa mirada, al reflejar el cuerpo de Paloma, la estimula a seguir girando en ese movimiento sin fin que es el movimiento del deseo. Y en el centro de ese movimiento está la mirada, el acto de contemplación que asemeja el cuerpo del erotismo al cuerpo de la pintura o del arte en general. Ya Huberto Batis, refiriéndose a los ensayos sobre artes plásticas de García Ponce, había señalado: "En las artes plásticas —a cuyo examen ha contribuido poderosamente- García Ponce descubre que el arte no reproduce lo visible, sino que hace visible [lo invisible]" (2004: 204). Y es precisamente eso a lo que ha dado lugar la mirada de Gilberto sobre el cuerpo de Paloma: esa mirada no se conforma con lo que ve, con lo que tiene ante los ojos; incisiva, hace que de ese cuerpo broten y se manifiesten instancias de realidad hasta ese momento inexistentes, insospechadas. "Entonces —escribe Gilberto en su diario- no se vería la fijeza del arte convertida en una forma de vida sino el movimiento de la vida convertido en obra de arte" (García Ponce 1984: 68).

Y es tal vez esa reflexión la que lleva a Gilberto a capturar el movimiento del cuerpo de Paloma en la fijeza de un relato. Sin embargo, allí, en el desenvolvimiento de esa escritura, no sólo son dos cuerpos los que protagonizan la historia erótica que se trenza entre ellos. La inclusión de un tercero, la mirada que contempla el juego voluptuoso de esos cuerpos, resulta absolutamente necesaria a esa historia, como ha sido necesaria también en la propia vida de Gilberto y Paloma. Ahora, en el cuento de Gilberto, ese tercero que contempla la escena se materializará a través 
de la presencia de un gato. "El gato de tu cuento — le dice Paloma — es la mirada de los demás" (103). ${ }^{5}$

Como en un juego de cajas chinas o muñecas rusas, la escena se repite una y otra vez (de la realidad al cuento, del cuento a la pintura, de la pintura a la realidad misma) en el movimiento obsesivo y envolvente de la escritura. Si la escritura del cuento ha tomado a Paloma como modelo de una escena que podríamos calificar de perversa, ese movimiento no culmina ni se detiene en el cuento mismo. Es tan sólo un primer momento que habrá de desembocar en otra escritura, cuya función, en apariencia al menos en un principio, no sería más que repetir la misma escena, para dejar constancia así de un movimiento infinito. Antes de publicar el cuento, Gilberto le pide a Nicolás Cusade, un amigo pintor, que lo ilustre con una serie de viñetas, siguiendo para ello exclusivamente las imágenes inscritas en el cuento. "Tú limítate a decir lo que te hace pensar en términos de dibujo -le ordena-. Ya sabes que no espero otra cosa de ti" (125).

Con ello, lo que hace Gilberto, en realidad, es exigirle a Nicolás que sujete su escritura a la suya, que someta su libertad como artista a la libertad de una gramática previa (la del cuento) que funcionaría para él, para Nicolás, como una camisa de fuerza, como una cárcel. Ilustrar un cuento, es decir, obligar a la imagen pictórica a encadenar sus trazos a las imágenes del texto narrativo, a seguirlo minuciosa y obedientemente; en pocas palabras, a esclavizarse a él. Todo está ya en el cuento: el pintor, por lo tanto, no tiene más que seguirlo a través de imágenes que brotan del relato mismo y que quedarán encerradas en él. Toda la libertad y el deseo en la narración; toda la sujeción y un deseo vicario y sometido en los dibujos que la ilustran. Así, la escritura pictórica funcionaría nada más que como una escritura parásita de esa otra escritura soberana que, al alimentarla, la limita, que no le permite ningún movimiento propio, que la obliga a ceñirse a un movimiento textual preestablecido.

Sin embargo, ya desde un principio también, desde esa plática inicial entre Gilberto y Nicolás, la escritura esclava, aunque acepta las condi-

5 La presencia de un gato en la literatura erótica de Juan ha sido una constante desde 1972, año en el que se publica Encuentros, uno de cuyos cuentos se titula así, "El gato", y dos años más tarde, en 1974, será el título a una novela que publicará Sudamericana, en Buenos Aires. 
ciones que se le imponen, prefigura a su vez un mínimo conato de rebelión: "Tú eres el modelo [del cuento] —le dice Nicolás a Paloma—. ¿Me servirías también de modelo?" (124). Con ello, Nicolás intenta, al menos, introducir una mínima instancia de ese deseo, del que se le quería exiliar, en su propia escritura. Se someterá a la escritura literaria, sin duda; la seguirá puntillosamente, pero desde ahora, en sus viñetas, ya no aparecerá sólo el cuerpo imaginario producto del texto al que debía imitar, sino el propio cuerpo desnudo de Paloma modelando para él. Sólo después, a medida que el trabajo avanza en contacto con el cuerpo real de Paloma y con lo que secretamente le sugiere sólo a él, esa escritura parásita y esclava comenzará a reconocer sus propias instancias deseantes —al colocar en cierta posición un brazo o una pierna de Paloma, al volverla de espaldas, al obligarla a mostrar sus senos o su sexo- hasta dejarlas fluir y manifestarse libremente en los dibujos que debían tan sólo ilustrar el cuento. Es ese lento aprendizaje del deseo el que libera a los dibujos de Nicolás de la esclavitud y parasitismo a los que el cuento de Gilberto quería someterlos. "El señor, que ha intercalado al siervo entre la cosa y él — dice Hegel—, no hace con ello más que unirse a la dependencia de la cosa y gozarla puramente; pero abandona el lado de la independencia de la cosa al siervo, que la transforma [mediante el trabajo]" (118).

Es así como la imagen resultante de ese juego de escrituras sobre el cuerpo de Paloma llega a alcanzar una figura que ya no pertenece por entero a Gilberto, tampoco a Nicolás. En realidad, no pertenece a ninguno de los tres en concreto, sino que los recupera incluyéndolos y al mismo tiempo los trasciende a los tres, liberando a cada uno de su rol primigenio:

Fue entonces cuando vi el primer dibujo que me había hecho desnuda, pero todos tenían la misma sensualidad, una sensualidad que ya sólo les pertenecía a los dibujos y también seguía siendo mía y de Nicolás, de mi cuerpo y de su mirada, del mismo modo que era mía y de Gilberto y del cuento la sensualidad del cuento cuando me lo leyó por primera vez a solas. Supongo que toda esa suma es la que entrega el arte al divulgarse. Algo parecido es lo que comentó Gilberto al ver los dibujos: Nos pertenece a todos y no es de nadie (García Ponce 1984: 133-134). 
Y un poco más adelante, Paloma sintetiza, ya en ese nuevo plano de realidad al que los ha conducido el arte, lo que ese liberador juego de escrituras ha producido en ellos: "Entre nosotros tres había una forma de relación indefinible de la que yo no era el centro sino que el centro estaba fuera de todos, colocado entre la realidad del cuento, la de los dibujos y nuestra propia realidad" (135). Descentramiento, pérdida total de un centro que hace añicos esos roles iniciales: amo, esclavo y objeto del deseo. La imagen resultante de ese juego de escrituras libera por igual a los tres participantes de una posición fija en el movimiento del deseo, otorgándoles la posibilidad de que cada uno reconozca su infinita movilidad en el deseo a través de ese juego de escrituras sin centro que la novela de García Ponce escenifica.

Pero al igual que un cierto movimiento del arte desemboca en una realidad nueva para ellos, esa nueva realidad que comienzan a experimentar ahora los tres deberá insensiblemente desembocar también, como una suerte de paráfrasis necesaria, en el arte mismo, estableciéndose así un juego especular entre arte y realidad que no sólo altera el estatuto propio de cada uno de los elementos enfrentados haciendo que se contagien mutuamente, sino que reproduce la figura resultante, en la que arte y realidad se confunden, ante un espectador infinito, indeterminable. Esa mañana, en la que el último dibujo habrá de quedar concluido, Gilberto ha llevado jamón, queso, paté y vino al estudio de Nicolás para almorzar con él y Paloma en cuanto terminen el trabajo. Una vez que el último trazo queda cifrado en el papel, Gilberto decide que no hay por qué demorar más el almuerzo, que ni siquiera necesitan cambiarse de ropa, y salen al jardín los tres exactamente como están en ese momento: ellos dos vestidos y Paloma desnuda, y se disponen a disfrutar de la comida y el vino, quizá sin darse cuenta que están reproduciendo involuntariamente un cuadro de Manet, Déjeuner sur l'herbe, ante ese espectador desprevenido y ubicuo que encarna la mirada anónima de los vecinos. Y, con ello, cierran ese círculo (nunca vicioso, siempre enriquecedor gracias a la presencia del deseo, ese duende impertinente) que va del arte a la vida y de la vida al arte, borrando incesantemente las fronteras que los separan.

Si algo podemos constatar en la narrativa de Juan García Ponce, y en particular en sus novelas breves, es esa constante insistencia por no seguir el curso de la moral instituida, por rechazar las normas que la sociedad es- 
tablece para inducir los comportamientos adecuados y convenientes, por escapar a todo sistema de reglas y convenciones cuyo fin no es otro que disciplinar la conducta de acuerdo con los estatutos que la ley y el orden imponen para alcanzar una vida virtuosa. Esto lo ha señalado Ángel Rama en pocas palabras y de una manera concluyente: "La actitud de rechazo a las obligaciones del orden social urbano recorre toda la literatura de García Ponce" (188-189). Esta afirmación la comparte, en términos generales, la mayor parte de la crítica sobre la obra del narrador yucateco. ${ }^{6}$

$\mathrm{Y}$, en realidad, la literatura que a Juan le interesa es la literatura tránsfuga, aquella que deserta de los discursos insertos en la tradición y en la doxa para aventurarse a explorar caminos alternativos, sinuosos, abiertos a lo desconocido, que quizá no llevan a ninguna parte, que quizá sólo se buscan la cola, como algunas serpientes. Me parece que en esta búsqueda de lo incierto, de lo irregular, de lo fortuito, de lo inconveniente incluso, radica una buena parte de la poética del escritor yucateco, esa poética que transita por igual en sus cuentos y en sus novelas, en su teatro y en sus ensayos, desde la lucidez agonal que la caracteriza, y que no sólo ha tratado de recuperar esas zonas oscuras, en muchos casos perversas y pocas veces accesibles a la razón que de alguna manera nos recorren a todos, sino que ha logrado edificarse en ellas, a contracorriente incluso de los impolutos discursos oficiales que la rodean. Es precisamente a esta actitud literaria a lo que Georges Bataille habría calificado como una "estética maldita" (cfr. 1981), en la medida en que no se estructura sobre la base de los códigos y las normas socialmente establecidos, sino mediante su constante alteración.

Debo decir, para concluir estas notas, que los "caminos del mal" nunca le fueron ajenos a Juan García Ponce.

\section{Bibliografía}

Barthes, Roland. Fragmentos de un discurso amoroso. México: Siglo XXI, 1984. Bataille, GeOrges. La literatura y el mal. Madrid: Taurus Ediciones, 1981.

BAtIS, Huberto. "La obra literaria de Juan García Ponce", en Armando Pereira (ed.). La escritura cómplice. Juan García Ponce ante la crítica. México: Era /

6 El panorama de la crítica sobre la obra de Juan García Ponce ha sido ampliamente desarrollado en mi libro: La escritura cómplice. Juan García Ponce ante la crítica. 
Universidad Nacional Autónoma de México. Coordinación de Difusión Cultural, 1997. 64-82.

Batis, Huberto. Crítica bajo presión. Prosa mexicana 1964-1985. México: Universidad Nacional Autónoma de México. Coordinación de Humanidades, 2004 (col. Poemas y Ensayos).

Bauman, Zygmunt. Tiempos líquidos. Vivir en una época de incertidumbre. México: Tusquets Editores, 2009.

Deleuze, Gilles y Félix Guattari. Mil mesetas. Capitalismo y esquizofrenia. Valencia: Pre-Textos, 2000.

García Ponce, Juan. La casa en la playa. México: Joaquín Mortiz, 1966.

García Ponce, Juan. Unión. México: Joaquín Mortiz, 1974.

García Ponce, Juan. Figura de paja. México: Joaquín Mortiz, 1979.

García Ponce, Juan. Figuraciones. México: Fondo de Cultura Económica, 1982.

García Ponce, Juan. De ánima. México: Montesinos, 1984.

Gorostiza, José. Poesía. México: Fondo de Cultura Económica, 1964.

HeGel, G. W. F. Fenomenología del espíritu. México: Fondo de Cultura Económica, 1973.

Klossowski, Pierre. La revocación del Edicto de Nantes. México: Era, 1975a.

Klossowski, Pierre. Roberte esta tarde. México: Era, 1975b.

KRISTEVA, Julia. Historias de amor. México: Siglo XXI, 1988.

LACAN, JaQues. El seminario. Barcelona / Buenos Aires: Ediciones Paidós, 1981.

NietzSCHE, Friedrich. La genealogía de la moral. Madrid: Alianza Editorial, 1983.

Pereira, Armando. La escritura cómplice. Juan García Ponce ante la crítica. México:

Era / Universidad Nacional Autónoma de México. Coordinación de Difusión Cultural, 1997.

RAMA, ÁNGEL. "El arte intimista de Juan García Ponce", en Jorge Lafforgue. Nueva novela latinoamericana 1. Buenos Aires: Paidós, 1969 (col. Letras Mayúsculas).

Sartre, Jean-Paul. Los caminos de la libertad. Buenos Aires: Losada, 1967a.

SARTRE, JeAn-PAul. La edad de la razón. Buenos Aires: Losada, 1967b.

SARTRE, JeAn-PAul. El ser y la nada. Buenos Aires: Losada, 1967c.

TANIZAKI, JUNICHIRO. The key. New York: Alfred A. Knopf, 1961.

\section{ARMANDO PEREIRA}

Se doctoró en Letras por la UNAM en 1992. Es investigador del Instituto de Investigaciones Filológicas y profesor en la Facultad de Filosofía y Letras de la UNAM. Sus áreas de especialización son Literatura Latinoamericana y Literatura Mexicana del siglo xx. Actualmente imparte el curso sobre "Narradores mexicanos de la Generación de Medio Siglo" en el Posgrado en Letras de la Facultad de Filosofía y Letras de la UNAM. Es miembro del Sistema Nacional de Investigadores y de la Asociación Internacional de Hispanistas. 